J. Neurol. Neurosurg. Psychiat., 1954, 17, 250.

\title{
THE TREATMENT OF MANIC PSYCHOSES BY THE ADMINISTRATION OF LITHIUM SALTS
}

\author{
BY \\ M. SCHOU, N. JUEL-NIELSEN, E. STRÖMGREN, and H. VOLDBY \\ From Aarhus University Psychiatric Institute, Sindssygehospitalet, Risskov, Denmark
}

The treatment of manic psychoses with lithium salts was introduced by Cade in 1949, following an accidental observation of a sedative-like action of lithium ions when administered to guinea-pigs. Beneficial effects of this treatment in cases of mania have also been reported by Ashburner (1950) and by Noack and Trautner (1951).

According to these reports the effects of lithium treatment are striking, and it is rather astonishing that this observation has failed to arouse greater general interest among psychiatrists. One possible reason may be that the doses reported necessary for a clinical effect are close to those giving rise to toxic symptoms. Another explanation may possibly be found in the difficulties encountered in attempts to convey to others in a quantitative manner the clinical impressions of the effect of a new psychiatric therapy. The proper evaluation of a psychiatric therapy is a matter of considerable difficulty for the following reasons : (1) An objective, quantitative assessment of the degree of the psychosis is often difficult or impossible, and usually the evaluation of the effect of a new therapy has to be based on a clinical estimate. (2) Unless special precautions are taken, the therapeutic effect and its evaluation are liable to gross distortions due to suggestibility, negative or positive, in the patients as well as in the observers. (3) Most psychoses, and notably manias and depressions, show spontaneous variations in duration and intensity. For this reason it is not always evident whether an improvement occurring concomitantly with the administration of a certain therapy is spontaneous or due to the therapy given.

The purpose of the present study has been to try out the lithium treatment of manic psychoses in such a way that these sources of error and uncertainty were reduced as much as possible.

\section{Material and Procedure}

Patients.-The material consists of 38 manic patients, 21 females and 17 males. They may be clinically divided into two groups.
Typical Cases.-These were the "pure" manias without any atypical symptoms, cases in which there was no doubt as to the diagnosis of manicdepressive psychosis at any stage of the disease. Delusions, if present, were in obvious accordance with (and most probably secondary to) the patient's mood. Hallucinations were absent or inconspicuous. Contact was always easily obtained with these patients.

Atypical Cases.-The clinical picture was more or less tainted with atypical symptoms : delusions without overt relation to the mood and probably with a katathymic background, hallucinations of more than episodic character, periods with reticence and contact difficulties, gross hysterical symptoms, etc. In all these cases, however, the course of the disease and the frequent appearance of "pure" phases did not leave any doubt as to the diagnosis of a manic-depressive insanity.

Clinical Assessment.-The patients under lithium treatment were all placed in a few special wards to ensure constancy in the observation by the ward personnel and the psychiatrists. The emotional level and the motor activity of the patients were registered daily on a three-point scale, using the values,+++ , and +++ to indicate the various degrees of the mania.

Administration of Lithium.- - In some cases the lithium was given in an "open" treatment for a certain period. In other cases a "blind" scheme was adopted : the patients received lithium salts or placebos for a short period, usually two weeks ; the tablets were distributed by the biochemist in boxes labelled with consecutive numbers, and neither the patients, the ward personnel, nor the psychiatrists knew whether the tablets contained lithium or were placebos. The biochemist did not see the patients or take part in the clinical evaluation. Every two weeks the medication was shifted in a random manner from lithium to placebo and vice 
versa, and changes from lithium to lithium and from placebo to placebo were also used. The content of each series of tablets was not disclosed until the clinical data had been evaluated and tabulated. All tablets were of the same dimensions and colour ; they were given pulverized and in a liberal quantity of sugar to cover possible differences in taste. Care was taken to ensure that all was swallowed.

The lithium salts were lithium carbonate, lithium citrate, and lithium chloride, and the tablets contained equivalent amounts of lithium ; the lithium content of the tablets was checked occasionally by analysis. (Lithium chloride is highly hygroscopic and impractical to dispense as tablets. In the few instances where it was employed the tablets had to be kept in a desiccator.) The placebo tablets contained lactose, sodium bicarbonate, or potassium bicarbonate ; the latter two contained carbonate in amounts equivalent to the lithium carbonate tablets.

The patients had the ordinary hospital diet without any restrictions in sodium chloride intake. Extra medication, including the use of sedatives, was avoided as far as possible, and E.C.T. was not given during the period of lithium treatment. The lithium treatment was usually preceded by a short period without any medication during which the pre-treatment clinical state was assessed.

The dosage of lithium will be apparent from the case reports. It was of the same order of magnitude as that used by Noack and Trautner (1951), although on the whole somewhat smaller, usually 24 to 48 $\mathrm{mEq}$. per day, corresponding to a daily intake of 0.9 to $1.8 \mathrm{~g}$. of lithium carbonate. Only in a few instances was a higher dose used.

Laboratory Tests. - In the first part of the study pulse, blood pressure, and temperature were measured daily, but later this was not found necessary as a routine. During treatment with both lithium salts and placebos the following laboratory estimations were carried out regularly, usually once a week or once every second week, but frequently more often: haemoglobin, sedimentation rate, total leucocyte count and differential count, blood urea, urine glucose, urine protein, and electrocardiogram. Serum sodium, potassium, and lithium concentrations were determined in a Beckman flame photometer (model 9200) by a modification of the method described by Beckman Instruments, Inc. (Beckman Application Data DU-12-B). The same tests were made before lithium treatment was started. In some cases the E.E.G. was recorded during lithium and placebo periods, and in a few instances the lithium concentration in the cerebrospinal fluid was measured. Both serum and spinal fluid lithium concentrations were kept secret from the observers.

\section{Results}

Psychiatric Effects.-The data from some representative cases are presented in graphs. The wavy line indicating the degree of the psychosis has been plotted according to a joint evaluation of the daily notes on emotional level and motor activity. In most cases these two varied together rather closely. In a single patient (Case 34) an unmistakable dissociation was observed during lithium treatment; the emotional level is here depicted as a line of crosses and the motor activity as a line of dots. In some of the cases part of the curve is only fragmentary because the clinical notes were too scarce to permit a proper evaluation of the degree of mania during these periods. Sometimes the clinical assessment was only secondhand, e.g., the evaluation of the patient's state before admission or after discharge, which was based on information obtained from relatives or from the patient himself ; in these cases the curve appears as a broken line. The periods with "open" and "blind" treatment are not distinguished in the graphs, but usually treatment-periods of less than one month have been part of the "blind" experiment. In the legends are presented short case histories ; the ages and weights refer to the time of discharge or, for the patients still in the hospital, to May 1, 1954.

The total response of each patient to the therapy has been classified as "+ effect", " possible effect", or " - effect" (Table I). In order to be classified

TABLE I

THE EFFECT OF LITHIUM TREATMENT

\begin{tabular}{cc|c|c|c|c}
\hline & & \multicolumn{4}{|c|}{ No. of Cases } \\
\cline { 3 - 6 } & & + Effect & $\begin{array}{c}\text { Possible } \\
\text { Effect }\end{array}$ & -Effect & Total \\
\hline Typical cases & $\ldots$ & 12 & 15 & 3 & 30 \\
Atypical cases & $\ldots$ & 2 & 3 & 3 & 8 \\
\hline Total $\ldots$ & $\ldots$ & 14 & 18 & 6 & 38 \\
\hline
\end{tabular}

under "+ effect" a case must fulfil one or more of the following criteria : (a) In a patient with manic attacks occurring at regular intervals lithium treatment was able to prevent these attacks (see Cases 1 and 2$) ;(b)$ in a patient with constantly elevated emotional and/or motor level the degree of the mania decreased during periods of lithium administration and increased during placebo periods (see Cases 4,5 , and 6$) ;(c)$ in a patient with a mania that changed rapidly and fortuitously in intensity 
before treatment continuous lithium treatment was accompanied by a neutral period that was significantly longer than the spontaneous neutral phases (see Case 12$) ;(d)$ in a patient with previous manic attacks of very regular duration lithium treatment brought about a significant shortening of the phase (see Case 14).

The group "possible effect" includes cases in which lithium treatment was accompanied by a distinct improvement of the condition, but in which a spontaneous cessation of the manic period could not be excluded (see Cases 15, 16, and 17), and cases in which lithium treatment appeared to influence the disease beneficially, but in which the improvement was not as clear-cut as in the cases classified under "+ effect" (see Case 28).

"Minus effect" means that treatment with proper doses of lithium ( 24 to $48 \mathrm{mEq}$. per day) for a proper length of time (two weeks or more) failed to influence the mania beneficially (see Cases 33,34 , and 35 ).

In a small number of treated patients the effect of lithium could not be established because the period of administration was too short, the dosage too small, or the observation for various reasons not quite reliable.

Our results are in essential agreement with those of the Australian psychiatrists; lithium has an unquestionably beneficial effect on a number of manic patients. So far as our observations go, they indicate that the effect is only symptomatic; when lithium administration is stopped the manic symptoms reappear unless the manic phase has subsided spontaneously in the meantime. Only in a single patient (Case 14) did we observe an effect that gave the impression of a shortening of the manic phase. A similar "curative" effect of lithium is possible in other cases (e.g., Case 15), but a proper evaluation of the effect is not possible because the spontaneous duration of the manic period is not known.

Some of the cases classified under "possible effect" have probably also reacted favourably to lithium, but the reaction could not be established unequivocally. This was the case when E.C.T. had been given so frequently or when the case history was so short that the spontaneous, i.e., untreated, course of the disease could not be estimated. Fourteen of the 18 cases in this group belong to this category. In the remaining four cases the lithium treatment appeared to influence the disease by preventing, partially or totally, manic attacks which occurred frequently and irregularly before the treatment, but the treatment has as yet not been given for a sufficiently long time to permit a classification under "+ effect".
Six patients did not respond to lithium treatment. In Case 33 the mania continued unchanged during lithium treatment whereas E.C.T. caused an improvement that was marked, if only of short duration. It cannot be excluded, of course, that treatment with higher doses of lithium and for a longer time might have been effective. Case 34 presents some interesting features; during the lithium treatment in 1952 the condition was not improved but a certain effect of lithium was probable because the patient during treatment showed a distinct dissociation between the emotional level and the motor activity. In 1954 lithium treatment was instituted once more, as short periods of lithium administration alternating with placebo periods. The patient's response was not in phase with the lithium periods, but nevertheless the condition improved gradually, and in May, 1954, the patient was in a far better condition than he had been for the last two years. It is of interest to note that even during the highest lithium dosage the serum lithium concentration in this patient never exceeded $0.8 \mathrm{mEq}$. per litre. During the first lithium period of Case 35 the mania disappeared in about three weeks, but during the second and third lithium periods (April-May, 1954) a manic attack occurred in spite of a dosage of $48 \mathrm{mEq}$. of lithium per day. This observation necessitates a classification under " - effect". Cases 36, 37, and 38 were all atypical manic-depressive psychoses and showed only insignificant clinical change during lithium treatment. In Case 36 a maximal value of $3.0 \mathrm{mEq}$. lithium per litre serum was reached; this is, with the exception of Case 39, the highest serum lithium concentration observed, and the patient had no symptoms of intoxication at the time.

The " + effect" group includes patients with short case histories as well as very long ones, e.g., 35 years in Case 1. It will be observed, however, that with the criteria for "+ effect" employed here most of the cases with a short duration of the disease will necessarily be classified under " possible effect", even if lithium has actually been effective. It is striking that 11 of the 14 cases in the " + effect " group were women. It may be of significance in this connexion that generally higher serum lithium concentrations were reached in the women than in the men (see laboratory findings). But our material is admittedly too small to permit any conclusions regarding the relative effectiveness of lithium treatment in cases of long and short duration, in women and men, in old and young persons.

Noack and Trautner (1951) found lithium carbonate and lithium citrate equally effective whereas lithium chloride was of much less therapeutic value. 
We have mainly used the first two salts and have found that in some patients lithium citrate is apparently somewhat less effective than the carbonate ; however, the number of observations is too small to warrant any definite conclusions (Table II).

TABLE II

CLINICAL EFFECT OF LITHIUM CARBONATE AND LITHIUM CITRATE

\begin{tabular}{l|c|c|c|c}
\hline \multicolumn{1}{c|}{ Shift of Medication } & \multicolumn{2}{|c}{$\begin{array}{c}\text { During Two Weeks } \\
\text { after Change of } \\
\text { Medication the } \\
\text { Patient }\end{array}$} \\
\hline From & To & $\begin{array}{c}\text { Became } \\
\text { More } \\
\text { Manic }\end{array}$ & $\begin{array}{c}\text { Was Un- } \\
\text { changed } \\
\text { Manic }\end{array}$ & $\begin{array}{c}\text { Became } \\
\text { Less } \\
\text { Manic }\end{array}$ \\
\cline { 2 - 5 } Nothing or placebo & Lithium carbonate & 2 & 11 & 40 \\
Lithium carbonate & Nothing or placebo & 8 & 9 & 0 \\
Nothing or placebo & Lithium citrate & 0 & 6 & 5 \\
Lithium sitrate & Nothing or placebo & 6 & 0 & 0 \\
\hline
\end{tabular}

In part of the study sodium and potassium bicarbonate tablets were used as placebos, and the dosage was such that the amount of carbonate was equivalent to the carbonate administration during treatment with lithium carbonate. Table III shows that the carbonate ion in itself is therapeutically ineffective.

TABLE III

CLINICAL EFFECT OF CARBONATE ION

\begin{tabular}{|c|c|c|c|c|}
\hline \multicolumn{2}{|c|}{ Shift of Medication } & \multicolumn{3}{|c|}{$\begin{array}{l}\text { During Two Weeks } \\
\text { after Change of } \\
\text { Medication the } \\
\text { Patient }\end{array}$} \\
\hline \multirow[t]{2}{*}{ From } & \multirow[t]{2}{*}{ To } & $\begin{array}{c}\text { Became } \\
\text { More } \\
\text { Manic }\end{array}$ & $\begin{array}{c}\text { Was } \\
\text { Un- } \\
\text { changed }\end{array}$ & $\begin{array}{l}\text { Became } \\
\text { Less } \\
\text { Manic }\end{array}$ \\
\hline & & \multicolumn{3}{|c|}{ Number of Observations } \\
\hline Nothing or lactose & $\underset{\text { bonate }}{\mathrm{Na}}$ or $\mathrm{K}$ bicar- & $\mathbf{0}$ & 5 & 1 \\
\hline$\underset{\text { bonate }}{\mathrm{Na} \text { or } \mathrm{K} \text { bicar- }}$ & Nothing or lactose & 0 & 9 & 0 \\
\hline$\underset{\text { bonate }}{\mathrm{Na} \text { or } \mathrm{K} \text { bicar- }}$ & $\underset{\text { bonate }}{\mathrm{Na}}$ or $\mathrm{K}$ bicar- & $\mathbf{0}$ & 4 & 1 \\
\hline Nothing or lactose & $\begin{array}{l}\text { Nothing or lac- } \\
\text { tose }\end{array}$ & $\mathbf{0}$ & 4 & 0 \\
\hline
\end{tabular}

The effect of lithium in cases of mania differs markedly from a simple sedation. First, in many of the cases that responded to lithium therapy rather massive doses of barbiturates and other sedatives given previously had only affected the condition slightly; secondly, when the patients had been neutralized by lithium therapy they did not give the impression of being "drugged" as patients commonly are after large doses of sedatives. Some of the patients explained, while being kept on a maintenance dose, that they "did not feel quite their own self", they were " bored" and slightly ill at ease. One patient expressed a feeling of being somehow "kept down" by the tablets. These sensations may conceivably be symptoms of an intoxication which is so slight that it does not give rise to more tangible toxic symptoms. A different explanation seems also possible. Several of these patients had been exalted and hyperactive for years before the lithium treatment was instituted. When these feelings of elation and excess of energy were gone, the patients felt changed and lacked something without being actually depressed. Only in five instances was a transition into a depressive state observed, and lithium administration was then stopped. The depression lasted from a few days (e.g. Case 16) to several months, but since these patients had previously had both manic and depressive periods, it seems doubtful whether the lithium treatment can be considered responsible for the depressions observed. Noack and Trautner (1951) found that the depressive phases of manic-depressive psychoses were unaffected or in some cases aggravated by treatment with lithium salts; for this reason we have not given lithium to depressed patients.

Intoxication.-Our observations on lithium intoxication are in agreement with the findings of Cade (1949) and Noack and Trautner (1951). The doses necessary for a therapeutic effect are not far from the doses giving rise to slight intoxication. As an example may be mentioned Case 4 : when a dose of 16 to $24 \mathrm{mEq}$. lithium per day was given the mania usually abated in two to three weeks and no toxic symptoms developed. If the dose was increased to $48 \mathrm{mEq}$. per day, the patient became neutral in less than one week, but after three to four days of medication the patient experienced nausea, diarrhoea, and tremor of the hands. When the dose was again reduced to $24 \mathrm{mEq}$. per day, the toxic symptoms disappeared after one to two days while the clinical improvement lasted. Apparently $24 \mathrm{mEq}$. of lithium per day was the proper maintenance dose for this patient.

The most frequent toxic symptoms were nausea and vomiting, diarrhoea, tremor of the hands, a feeling of general fatigue, and slight drowsiness. Occasionally we observed blurred vision, vertigo, uncertain gait, slight confusion, and dryness of the mouth. Intoxication was very seldom seen on a dosage of $24 \mathrm{mEq}$. per day, whereas $48 \mathrm{mEq}$. 
per day led to slight toxic symptoms in about onefourth of the cases. The intoxication usually disappeared after a few days when lithium administration was stopped or the dose reduced. Toxic symptoms were never seen earlier than after three to four days of lithium administration.

Laboratory Findings.-The laboratory investigations in this study were made with the purpose of serving as a rough control of the treatment and a safeguard against grave intoxications. Our laboratory facilities did not permit a systematic study of the biochemical changes occurring in blood and urine during lithium treatment.

Neither the slight toxic symptoms observed in a number of patients nor the therapeutic effect of lithium treatment were accompanied by any consistent changes in the composition of blood and urine, and it may be of interest to point out specifically that lithium treatment did not induce significant changes in serum sodium and potassium concentrations. We are in complete agreement with Noack and Trautner's statement : "So far it has not been possible to find a laboratory test which would indicate optimum dosage or impending intoxication, and which could replace the careful observation of the patient."

The serum lithium level varied usually between 0.5 and $2.0 \mathrm{mEq} . / 1$. during treatment. $A$ serum lithium concentration of $4.5 \mathrm{mEq}$. $/ 1$. was observed in one patient (Case 39) who died from an anaemic infarction in the pons (verified by necropsy) after nine days of lithium administration. She was 71 years old, strongly arteriosclerotic, and had had one previous vascular attack during a manic explosion. Lithium treatment was instituted in the hope of preventing her frequent, violent manic outbursts. We consider it very unlikely that the lithium medication was responsible for the occurrence of the infarction but rather think that the high serum lithium level may have been caused by a sudden impairment of the patient's general biological functions.

The maximum serum lithium concentrations observed were somewhat higher in the women, excluding Case 39 (average $1.38 \mathrm{mEq}$./1., range $0.4-3.0 \mathrm{mEq} . / 1 ., \mathrm{n}=21$ ), than in men (average $1.04 \mathrm{mEq} . / 1$., range $0.4-1.6 \mathrm{mEq} . / 1 ., \quad \mathrm{n}=17$ ). As mentioned before, Case 36 did not show any signs of intoxication while having $3.0 \mathrm{mEq}$. lithium/1. serum ; on the other hand toxic symptoms have been observed in a patient with only $0.6 \mathrm{mEq}$. $/ 1$. serum. We feel, like Noack and Trautner, that the serum lithium level is not a reliable indicator of the lithium concentration in the tissues; nevertheless, it is our impression that a knowledge of the serum lithium concentration is of some value as a guide for the therapy, and we should be hesitant to institute lithium therapy under conditions where the serum lithium level could not be checked regularly.

The lithium concentration in the cerebrospinal fluid was determined in six cases about one to two weeks after the beginning of the lithium treatment. In all cases the lithium content was lower in the spinal fluid than in the serum, the average ratio being 0.47 (range $0.33-0.67$ ). Oberhard and Sserafimow showed in 1933 that lithium could pass the blood-cerebrospinal-fluid barrier, and Hanlon, Romaine, Gilroy, and Deitrick (1949) found in a case of lithium poisoning a spinal fluid lithium level of $1.5 \mathrm{mEq}$./1. while the serum concentration was $2.6 \mathrm{mEq} . / 1$.

In one patient (Case 24) lithium treatment caused transient changes in the electrocardiogram. Before treatment the E.C.G. showed slight left axis deviation but was normal in other respects. Lithium, $48 \mathrm{mEq}$. per day, was given from January 18 to January 30 , 1953 ; on January $26 T_{1}$ was slightly inverted and $\mathrm{T}_{2}$ isoelectric, and on February 2, three days after lithium treatment was stopped, $T_{1}$ and $T_{2}$ were both inverted. This abnormality disappeared gradually during the following 10 days, and on February 14 the E.C.G. was identical with the one obtained before lithium administration. Lithium treatment was resumed in May, 1954, with doses of $40 \mathrm{mEq}$. per day, and similar changes occurred in the E.C.G., only less pronounced. No clinical symptoms of cardiac failure were observed during the treatment; the laboratory findings were all within the normal range, and the serum potassium level never fell below $3.5 \mathrm{mEq}$. $/ 1$. Electrocardiographic changes during lithium administration in man have been described only by Hanlon and others (1949) who observed a transient intraventricular heart block in a fatal case of lithium poisoning. Radomski, Fuyat, Nelson, and Smith (1950) gave rather large doses of lithium to dogs $(1 \cdot 2 \mathrm{mEq}$. per $\mathrm{kg}$. bodyweight). Shortly before death the E.C.G.s showed depressed $\mathrm{S}-\mathrm{T}$ segments, inverted $\mathrm{T}$ waves, and widening of the QRS complex. It should be noted that two of our patients (Cases 6 and 32) suffered from chronic auricular fibrillation; this was not influenced in any way by the lithium administration, and the patients stood the treatment well.

Occasionally lithium treatment gave rise to slight, reversible changes in the E.E.G. ; frequencies of 6 to 7 c.p.s. appeared, and the voltage was increased, but it did not exceed $100 \mathrm{mV}$. Changes of a similar type were found by Corcoran, Taylor, 
and Page (1949) in a patient intoxicated with lithium.

\section{Discussion}

Lithium was introduced into medicine by Garrod (1859) for the cure of gout and of urinary calculi ; it was given in doses varying from 12 to $80 \mathrm{mEq}$. per day (Daniels, 1914 ; Hare, 1916) usually as the carbonate. The theoretical consideration behind this therapy was that, since lithium urate is easily soluble, the lithium should dissolve the uric acid deposits around the joints and in the urinary tracts. Experiments later showed, however, that lithium is only a "solvent" for urates in concentrated solutions (Good, 1903), and lithium therapy of gout and uric acid calculi has now been abandoned.

Lithium bromide has been used against epilepsy in doses of 4 to $45 \mathrm{mEq}$. per day (Squire, 1916; Mitchell, 1870), but the alleged superiority of lithium bromide over other bromides does not appear to have been clearly demonstrated.

Some years ago lithium chloride was widely used as a taste substitute for sodium chloride in patients with cardiac disease who had to be kept on a salt-free diet. In a clinical trial with controlled doses of lithium chloride no untoward reactions were observed (Talbott, 1950), and the substance was eventually placed at the free disposal of the patients. But in 1949 several deaths due to lithium poisoning were reported (Corcoran and others; Hanlon and others), and the use of lithium chloride as a taste substitute has now come to an end.

Numerous toxic symptoms have been reported in the papers referred to during treatment with lithium (Cade, 1949 ; Corcoran and others, 1949 ; Good, 1903 ; Hanlon and others, 1949 ; Noack and Trautner, 1951 ; Roberts, 1950 ; Talbott, 1950) and also after experimental administration of lithium to man (Cleaveland, 1913) and animals (Foulkes, Mudge, and Gilman, 1952 ; Good, 1903 ; Masson, 1949 ; MacLeod, Swan, and Aitken, 1949 ; Radomski and others, 1950). They are listed here in an approximate order of frequency : nausea and vomiting, diarrhoea, tremor of the hands, muscular weakness and general fatigue, slight drowsiness, vertigo, uncertain gait, blurred vision, slurred speech, fasciculations in the facial muscles, mental confusion, slight depression, sweating, dryness of the mouth, tinnitus, lowering of blood pressure, reflex hyperirritability, coma, paralysis of the limbs, epileptic seizures, changes in the E.C.G. and E.E.G., lowering of body temperature, and diastolic heart stop (the last two only observed in animals).
Six deaths during lithium administration have been reported. In the first three (Corcoran and others, 1949; Hanlon and others, 1949), aged 70,66 , and 58, lithium chloride had been taken in excessive amounts in combination with a diet low in sodium chloride. The patients all developed coma combined with reflex hyperirritability and died less than a week later. In none of these cases was a necropsy performed. Roberts (1950) treated a chronic maniac in her fifties with 25 to $50 \mathrm{mEq}$. of lithium per day ; after a week she became confused and ataxic. Lithium administration was stopped, but the patient died on the fourteenth day after having had several epileptiform seizures. A post-mortem examination did not show any abnormalities in the central nervous system or elsewhere. Two more deaths during lithium therapy have been mentioned by Noack and Trautner (1951) but without any details. It seems likely that lithium administration has been responsible for at least some of these fatalities, but it is difficult to explain the mechanism or to identify those factors that make lithium therapy dangerous in some cases. Experiments with both man (Corcoran and others, 1949) and animals (Masson, 1949) show that restriction of sodium chloride intake should be avoided during lithium treatment, but future research will probably find additional factors that should be considered.

The psychiatric experiences with lithium are few. The authors all agree that lithium is ineffective or only slightly sedative in cases of depression and schizophrenia, but that considerable clinical improvement may be seen in cases of mania. All of the 10 cases treated by Cade (1949) responded favourably. Ashburner (1950) reports that of 50 patients treated with lithium about a dozen were able to leave hospital. Noack and Trautner treated more than 30 manic patients, and only one or two failed to show any response to the treatment. Our results are in line with these reports and show that in at least one-third of the cases the clinical improvement observed during lithium treatment is not due to inaccuracies in clinical assessment, suggestibility, or spontaneous variations.

So far the only effective treatment of mania has been electric convulsive therapy (E.C.T.), given as a series a shocks shortly after one another; but the duration of the improvement after this treatment is often so short that the practical therapeutic value of E.C.T. is considerably smaller during manic episodes than during depressions. The lithium therapy appears to offer a useful alternative since many patients can be kept in a normal state by administration of a maintenance dose. 
In an evaluation of the practical usefulness of this therapy the unquestionable toxicity of lithium has to be taken into account. The majority of the intoxications observed during lithium treatment of psychiatric patients have been only slight, and the toxic symptoms disappeared rapidly when lithium administration was discontinued. But the fact cannot be excluded that lithium therapy may be dangerous under special conditions of which our knowledge is still insufficient. A careful clinical and biochemical control of patients under lithium treatment appears advisable for the time being.

Quite distinct from the possible practical usefulness of lithium therapy in psychiatry is the theoretical significance of the observation that manic symptoms may be counteracted by the administration of lithium salts. The biochemical and physiological response of the organism to E.C.T. is complicated and largely unknown, and E.C.T. has, in spite of great expectations after its introduction into psychiatry, been of very limited value in the furtherance of our understanding of the pathophysiology of the manic-depressive psychosis. The administration of lithium salts appears to be a much less complicated procedure, and it does not seem unreasonable to expect that a study of the metabolic fate and the biological effects of lithium in experimental animals and in tissue preparations may yield useful information regarding the mechanism of its action in manic patients. Work along these lines is in progress in this hospital.

\section{Summary}

The effect of lithium salts on manic psychoses has been tested in a controlled experiment. During treatment the patients were under close clinical observation, and the effects of suggestibility were minimized by an alternation between periods of lithium and placebo administration; neither the patients nor the observers were told whether the tablets given contained lithium or were placebos. The effect of the treatment was evaluated with due consideration of the spontaneous course of the disease in each case.

Thirty-eight manic patients were treated. The response of 14 patients was classified as " + effect" ; in these cases it was highly improbable that the changes occurring during the treatment were due to spontaneous variations. Eighteen patients were grouped under the heading "possible effect"; the condition was improved during lithium administration but a spontaneous cessation of the mania could not be excluded. In six patients lithium treatment did not influence the mania beneficially; these were classified as " $\div$ effect ".
The therapeutic doses of lithium varied usually between 24 and $48 \mathrm{mEq}$. per day. On the higher dosage symptoms of slight intoxication were seen in some cases, the most frequent toxic symptoms being nausea and vomiting, diarrhoea, tremor of the hands, a feeling of general fatigue, and slight drowsiness. The symptoms of intoxication disappeared in three to four days when lithium administration was stopped.

Serum lithium levels were usually between 0.5 and $2.0 \mathrm{mEq} . / \mathrm{l}$. during treatment; the lithium content of the spinal fluid was considerably lower. In some patients lithium treatment gave rise to slight, reversible changes in the E.E.G. ; in a single patient transient inversions of the $T$ waves in the electrocardiogram were observed during the treatment.

It is concluded that lithium administration may be of considerable therapeutic value in a number of manic cases, but the danger of lithium intoxication necessitates a careful clinical and biochemical control.

Finally it is pointed out that the beneficial effect of lithium in cases of mania appears to offer new possibilities for a study of the pathophysiology of the manic-depressive psychoses.

Our thanks are due to Dr. H. C. Helsborg, Dr. K. Lundbaek, and Dr. A. Myschetzky for their assistance during various phases of the work. We wish to express our indebtedness to the Rockefeller Foundation for financial support and to the Williams-Waterman Fund for a research grant to one of us (M. S.), which made possible the purchase of a Beckman spectrophotometer.

\section{Addendum}

Since the manuscript was finished the following reports have come to our attention.

Despinois and de Romeuf (1951) and Deschamps and Denis (1952) reported good effects of lithium treatment in 10 and in four cases of mania respectively, and Lafon, Duc, and Maurel (1953) observed a sedative effect of lithium in cases of mania and schizophrenia. Carrère and Pochard (1954) found lithium of value as a sedative in eight cases of psychomotor excitation of various origin. Glesinger (1954) treated 104 patients with 7 to $43 \mathrm{mEq}$. of lithium per day. Of 21 manic patients, five responded very well, 10 responded well, and six failed to respond. Of the remaining patients, mostly schizophrenics, more than half responded very well to the treatment. About one-fourth of the patients had transient proteinuria. Gastro-intestinal symptoms were seen in seven patients and neurological symptoms (including nystagmus) in four patients, of whom one died. The necropsy showed encephalopathic changes. 


\section{REFERENCES}

Ashburner, J. V. (1950). Med. J. Aust., 37 (2), 386.

Cade, J. F. J. (1949). Ibid., 36 (2), 349.

Carrère, J., and Pochard (1954). Ann méd.-psychol., 112 (1), 566.

Cleaveland, S. A. (1913). J. Amer. med. Ass., 60, 722.

Corcoran, A. C. Taylor, R. D., and Page, I. H. (1949). Ibid., 139, 685

Daniels, A. L. (1914). Arch. intern. Med., 13, 480.

Deschamps, and Denis (1952). Avenir méd., Lyon, 49, 152.

Despinois, and Romeuf, J. de (1951). Rapport au Congrès des Neurologistes et Aliénistes de Langue française, Rennes. Quoted by Plichet, A. (1954). Presse méd. 62, 869 .

Foulks, J., Mudge, G. H., and Gilman, A. (1952). Amer. J. Physiol., $168,642$.

Garrod, A. B. (1859). Gout and Rheumatic Gout. Walton and Maberly, London.

Glesinger, B. (1954). Med. J. Aust., 41 (1), 277.

Good, C. A. (1903). Amer. J. med. Sci., 125, 273.
Hanlon, L. W., Romaine, III, M., Gilroy, F. J., and Deitrick, J. E. (1949). J. Amer. med. Ass., 139, 688.

Hare, H. A. (1916). The National Standard Dispensatory, 3rd ed. Philadelphia.

Lafon, R., Duc, N., and Maurel, H. (1953). Presse méd., 61, 713.

Masson, G. (1949). J. Amer. med. Ass., 139, 688.

MacLeod, J., Swan, R. C., and Aitken, G. A., Jr. (1949). Amer. J. Physiol., 157, 177.

Mitchell, S. W. (1870). Amer. J. med. Sci., 60, 443.

Noack, C. H., and Trautner, E. M. (1951). Med. J. Aust., 38 (2), 219.

Oberhard, I. G., and Sserafimow, B. N. (1933). Z. ges. Neurol. Psychiat., 147, 505.

Radomski, J. L., Fuyat, H. N., Nelson, A. A., and Smith, P. K. (1950) Fed Proc., 9, 310.

Roberts, E. L. (1950). Med. J. Aust., 37 (2), 261.

Squire, P. W. A Companion to British Pharmacopoeia. Cited by Cade. Ist ed. (1864); 19th ed. (1916), Churchill, London.

Talbott, J. H. (1950). Arch. intern. Med., 85, 1.

\section{Graphic Summaries of Representative Cases}

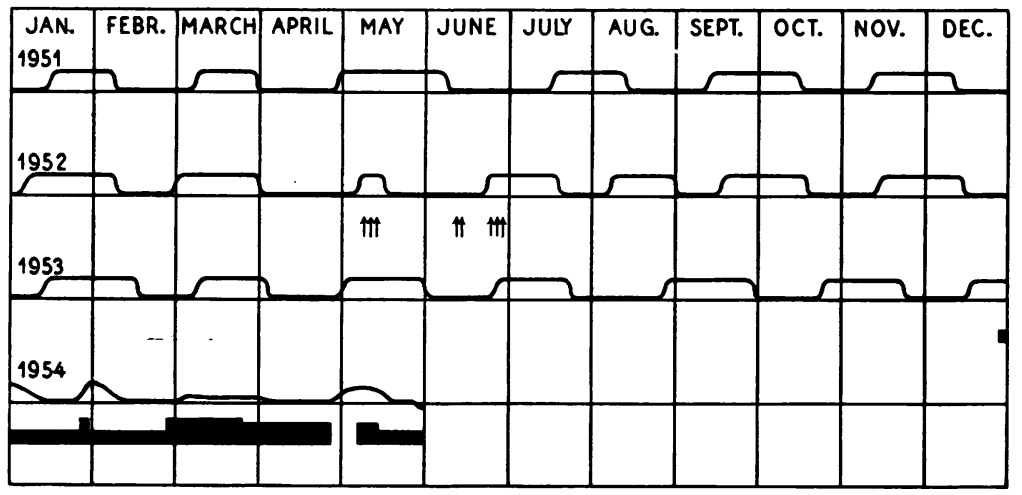

Case 1.-A woman, aged 61 (70 kg.), has been in a mental hospital for the last 35 years with regular attacks of mania. She has never had depressions.

Case 2.-A man, aged $52(67$ kg.), at 23 and at 30 years of age had depressions of short duration. For the last 21 years he has been in a mental hospital with regular attacks of mania but no depressions.

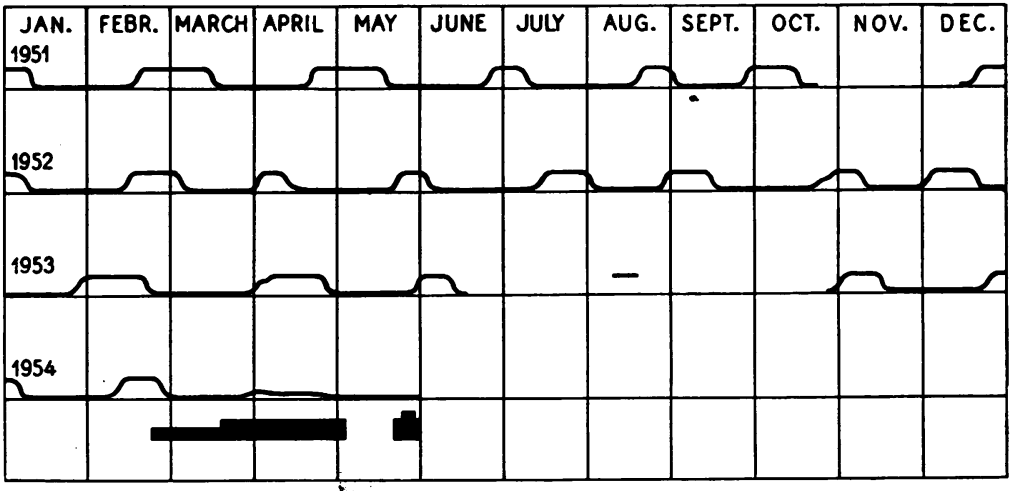

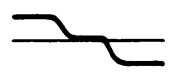

\lceil\rceil

$\uparrow$

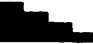

manic neutral

depressive

admitted, discharged

ECT lithium carbonate

lithium citrate

lithium chloride

placebo 


\begin{tabular}{|c|c|c|c|c|c|c|c|c|c|c|c|}
\hline $\begin{array}{l}\text { JAN. } \\
1952\end{array}$ & FEBR. & MARCH & APRIL & MAY & JUNE & JULY & AUG. & SEPT. & $\overline{O C T}$ & NOV. & DEC. \\
\hline 1953 & & & & & & & & & & & \\
\hline & & & & & & & & & & $\Gamma$ & \\
\hline 1954 & & & & & & & & & & & \\
\hline & & & & & & & & & & & \\
\hline & & & & & & & & & & & \\
\hline
\end{tabular}

Case 4.-A woman, aged 68 (72 kg.), at the age of 22 was depressed for one month. She was in a mental hospital for two years at 52-54 with irregular phases of mania and depression. From her sixty-second year she has been in a mental hospital, and during this time she has been almost constantly manic with only very brief neutral intervals.

Case 5.-A woman, aged 43 (53 kg.), had her first manic attack at 30 . Since then she has had frequent manic periods, varying in duration from a few months to some years, alternating with neutral phases. She has never had depressions.
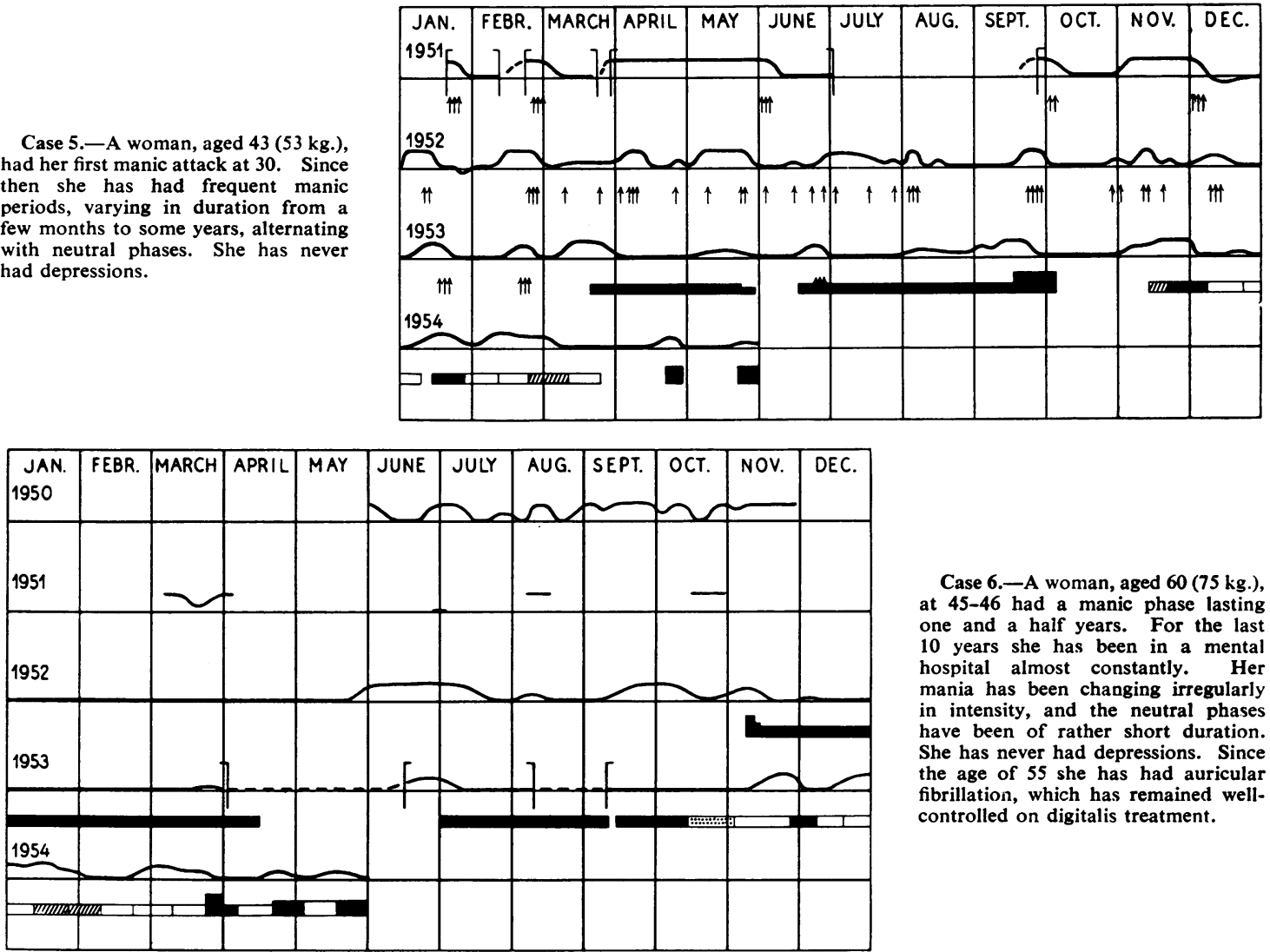

Case 6.-A woman, aged 60 (75 kg.), at 45-46 had a manic phase lasting one and a half years. For the last 10 years she has been in a mental hospital almost constantly. Her mania has been changing irregularly in intensity, and the neutral phases have been of rather short duration. She has never had depressions. Since the age of 55 she has had auricular fibrillation, which has remained wellcontrolled on digitalis treatment.

Case 12.-A woman, aged 63 (70 kg.), had short uncharacteristic psychotic episodes at 16 and at 30 . She had severe manic attacks of several months' duration at ages 49 , 56, and 57. In February, 1952, she had a short manic phase, and since July, 1952, she has been in a mental hospital.

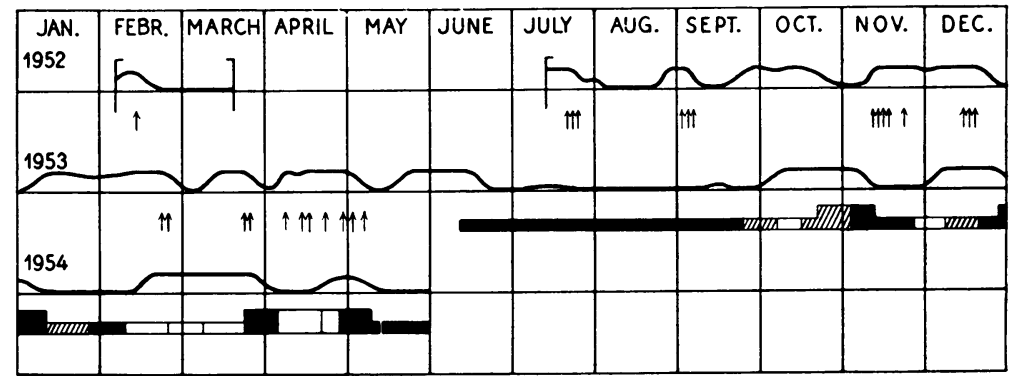


Case 14.-A woman, aged 50 (87 kg.), during a pregnancy at the age of 34 had a manic period of some months' duration. At ages 38, 42, and 45 she had manic phases which lasted three months each. She has never had depressions.

\begin{tabular}{|c|c|c|c|c|c|c|c|c|c|c|c|}
\hline $\begin{array}{l}\text { JAN. } \\
1941\end{array}$ & FEBR. & MARCH & APRIL & MAY & JUNE & JULY & $\begin{array}{c}\text { AUG. } \\
7\end{array}$ & SEPT. & OCT. & NOV. & DEC. \\
\hline 4945 & & & & & & & & & & & \\
\hline 1948 & & & & & & & & & & & \\
\hline 1949 & & & & & & & & & & & \\
\hline 1953 & & & & & & & & & & & \\
\hline & & & & & & & & & & & \\
\hline
\end{tabular}

\begin{tabular}{|c|c|c|c|c|c|c|c|c|c|c|c|}
\hline $\begin{array}{l}\text { JAN. } \\
1953\end{array}$ & FEBR. & MARCH & APRIL & MAY & JUNE & JULY & AUG. & SEPT. & OCT. & NOV. & DEC. \\
\hline$j^{1954}$ & & & & & & & & & & & Ant? $\uparrow$ \\
\hline & & & & & & & & & & & \\
\hline
\end{tabular}

Case 15.-A woman, aged 48 (61 kg.), had no psychotic phases before admission in 1953.

Case 16.-A man, aged 62 (69 kg.), at ages 26 and 45 had manic attacks of short duration. For the last eight years he has had irregular manic phases of one to two months' duration alternating with rather long neutral phases and with depressions lasting a few days.

\begin{tabular}{|l|l|l|l|l|l|l|l|l|l|l|l|}
\hline $\begin{array}{c}\text { JAN. } \\
1949\end{array}$ & FEBR. & MARCH & APRIL & MAY & JUNE & JULY & AUG. & SEPT. & OCT. & NOV. & DEC. \\
\hline 1951 & & & & & & & & & & & \\
\hline \\
\hline 1952
\end{tabular}

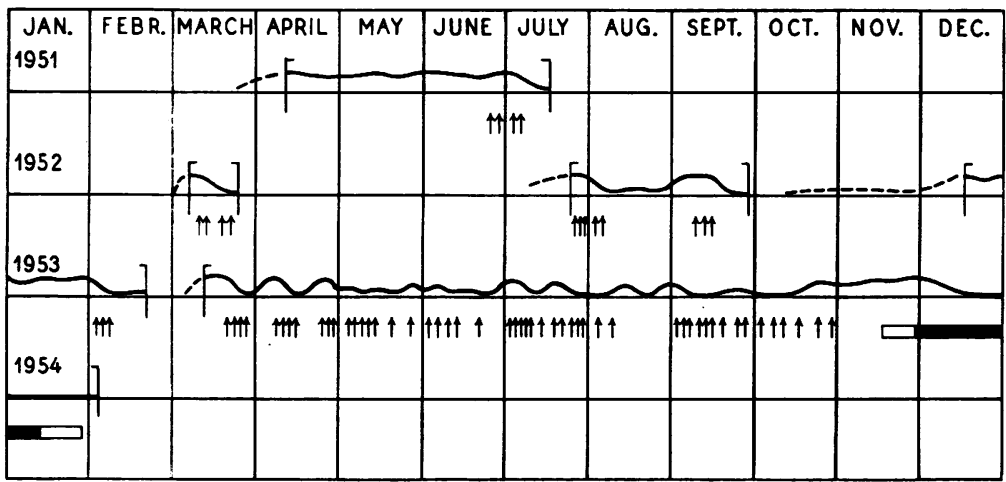

Case 17.-A woman, aged 40 $(52 \mathrm{~kg}$.$) , at the age of 35$ was in a mental hospital for eight months with a depression which later changed into a mania. Since 1951 she has had several manic phases but no depres. sions.

C 


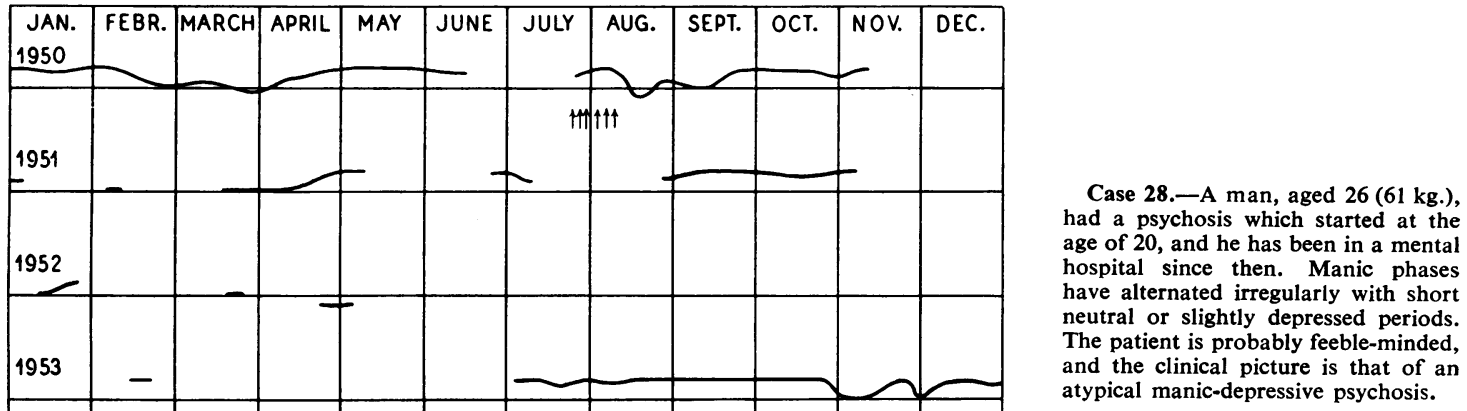

Case 35.-A man, aged $55(80 \mathrm{~kg}$.$) ,$ from the age of 21 had occasional periods of hypomania and slight depression, and at ages 40,42 , and 46 severe depressions. For the last seven years he has had frequent, irregular, severe manic attacks and a few short and slight depressions. During the last three years he has had four or five epileptiform seizures.
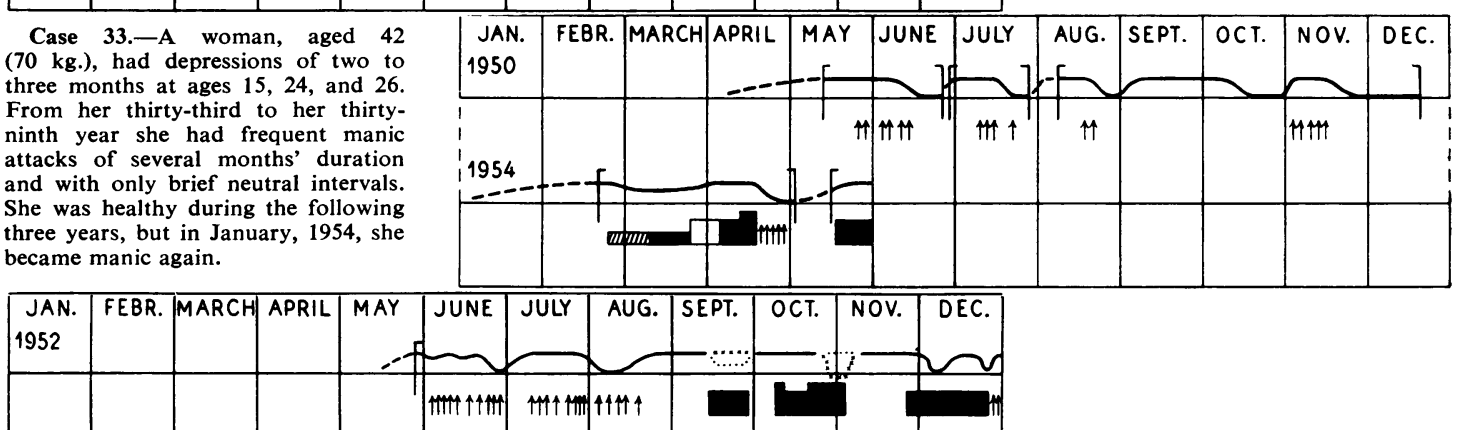

Case 34.-A man, aged 45 (68 kg.), had no psychotic phases before admission in 1952.
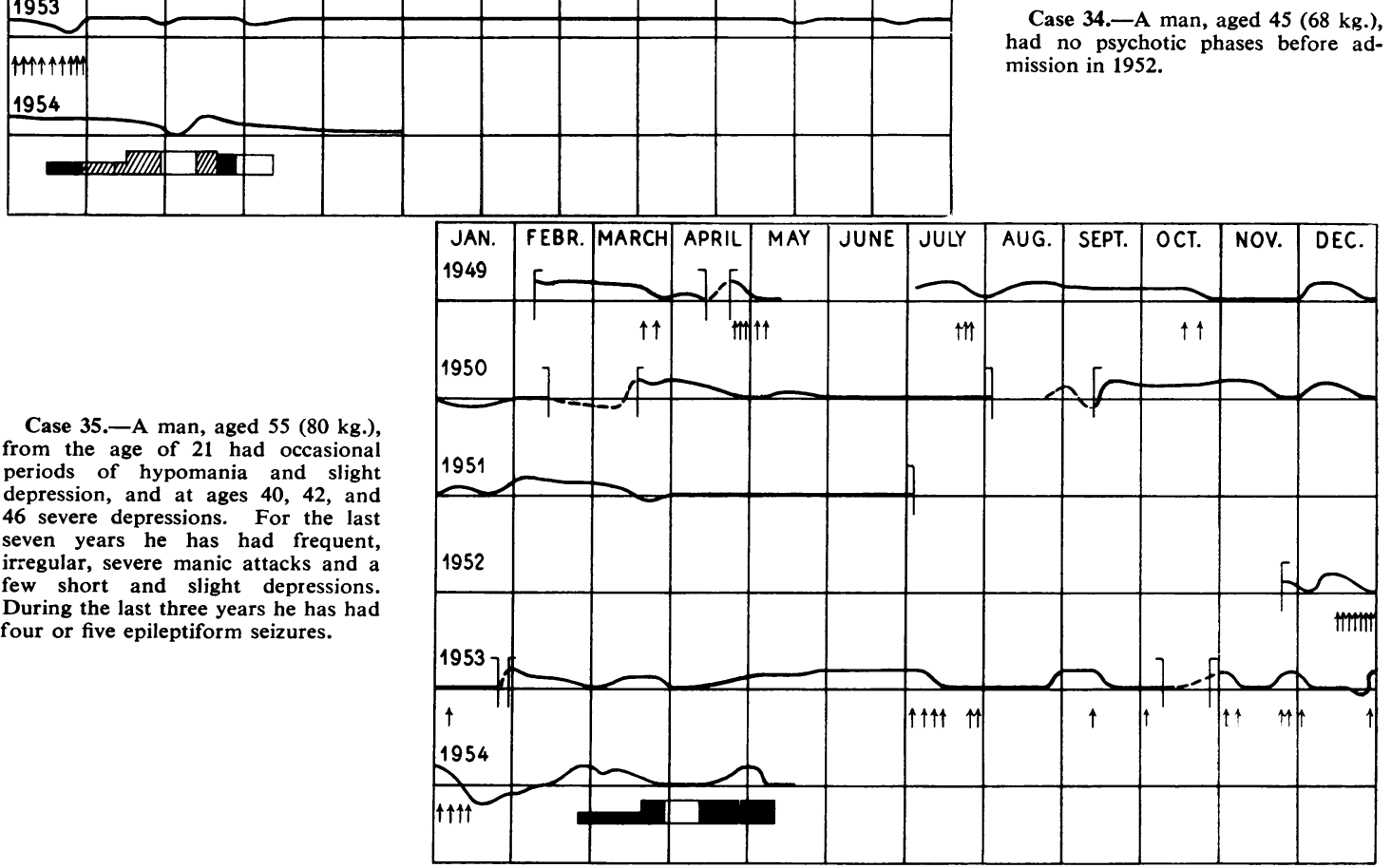